\title{
Applying Simulation Method in Formulation of Gluten-Free Cookies
}

\author{
Marina Nikitina ${ }^{1}$, Igor $_{\text {Nikitin }}{ }^{2,}$, and Vladimir Kulakov ${ }^{2}$ \\ ${ }^{1}$ Gorbatov's All-Russian Meat Research Institute, 109316 Moscow, Russia \\ ${ }^{2}$ Moscow State University of Technologies and Management named after K.G. Razumovskiy, 109004 Moscow, Russia
}

\begin{abstract}
At present time priority direction in the development of new food products its developing of technology products for special purposes. These types of products are gluten-free confectionery products, intended for people with celiac disease. Gluten-free products are in demand among consumers, it needs to expand assortment, and improvement of quality indicators. At this article results of studies on the development of pastry products based on amaranth flour does not contain gluten. Study based on method of simulation recipes gluten-free confectionery functional orientation to optimize their chemical composition. The resulting products will allow to diversify and supplement the necessary nutrients diet for people with gluten intolerance, as well as for those who follow a gluten-free diet.
\end{abstract}

\section{Introduction}

Celiac disease - an autoimmune enteropathy caused by eating gluten individuals with a genetic predisposition. This immune-mediated disease, wherein the deaminated peptides gliadin activate immune cells in the lamina propria of the small intestine, which stimulate $\mathrm{T}$ lymphocytes, whereby runs an adaptive immune response, resulting in increased production of interferongamma (IFN- $\gamma$ ) and Interleukin IL-15. All this leads to a pronounced infiltration intraepithelial lymphocytes and correspondingly to change and damage to the intestinal epithelium [1].

Celiac disease - a disease in which pathogenesis plays intake of foods containing gluten. Autoimmune process stops when the withdrawal of gluten from the ration, so there is the cessation of development of autoimmune enteropathy, followed by normalization of serum markers of disease.

One of the first advocates the philosophy of "Gluten Poison" became a cardiologist William Davis [2]. Based on his own research, he says, that gluten causes serious diseases, including arthritis and hypertension.

In 2011, there was another study: scientists from Monash University (www.monash.edu) came to the conclusion that the gastrointestinal diseases caused by consumption of gluten can occur even in those who do not have celiac disease. Especially true this statement is for people over 40 years, who have gluten entering the body in large amounts, causes inflammation of the intestinal wall. The implication of this - digestive disorders, the emergence of weight loss, decreased muscle activity.

These findings are confirmed by the experts of University of Maryland Baltimore Washington Medical Center (www.mybwmc.org), which found that gluten intolerance develops with age. It is manifested by flatulence, feeling of heaviness, digestive disorders that occur after the use of flour products.

The problem of intolerance to gluten is not confined to only one of celiac disease, often it causes food allergy in infants, manifestations of which may be quite varied: from skin rashes to chronic diarrhea. Currently, for example, school feeding organization provides for the development and implementation of diets mainly to healthy children, but there is the problem of catering to children with hereditary diseases, such as phenylketonuria, cystic fibrosis, celiac disease. Therefore, the development of gluten-free products and their inclusion in the diet of a particular category of patients in organized groups is relevant and requires further consideration.

In accordance with the international standards governing the quality of the food, gluten-free products can have it on label if level does not exceed $20 \mathrm{mg} / \mathrm{kg}$.

According to a survey Innova Market Insights, in 2014 the growth of production of gluten-free products amounted to $9 \%$ of total food and beverage products sold in the world. It is noteworthy that this figure was $17 \%$ in the US.

In April 2015 every 10th launched new product in the world was gluten free. The largest number of new products indicated in the bakery and confectionery industries (bread - 9\% of the total, cookies - $8 \%$ of the total volume of similar products). In other areas of the grocery market is also a growing interest in gluten-free products. More and more companies are joining the trend of exclusion of gluten from the products [3].

The main types of gluten-free vegetable raw materials in most gluten-free confectionery using amaranth, soy, peanut, pea, buckwheat flours, as well as various types of starches. The greatest interest in terms

Corresponding author: nikito.igor@gmail.com 
of enrichment of final product additional nutrients is amaranth flour. An analysis of the literature [4, 5] devoted to the study of complex processing of amaranth seeds, their chemical structure and pharmacological properties, characterizes them as a promising plant sources of protein, dietary lipids, dietary fiber and minerals, which shows the feasibility studies aimed at exploring the possibility of their use in the bakery and confectionery industry.

The content of essential amino acids and biological value of amaranth flour in comparison with wheat flour of the first grade is shown in Table 1 .

Table 1. The content of essential amino acids and biological value of amaranth and wheat flour

\begin{tabular}{|l|c|c|c|}
\hline $\begin{array}{c}\text { Name of } \\
\text { aminoacids }\end{array}$ & $\begin{array}{c}\text { Protein } \\
\text { FAO to protein }\end{array}$ & $\begin{array}{c}\text { Wheat flour } \\
1^{\text {st }} \text { grade, } \\
\text { gr } 100 \mathrm{gr} \\
\text { of protein }\end{array}$ & $\begin{array}{c}\text { Protein } \\
\text { Amaranth } \\
\text { flour semi- } \\
\text { skimmed, } \\
\text { gr / 100gr } \\
\text { of protein }\end{array}$ \\
\hline Isoleucine & 4.0 & 0.530 & 1.659 \\
\hline leucine & 7.0 & 0.813 & 2.279 \\
\hline Lysine & 5.5 & 0.265 & 3.692 \\
\hline $\begin{array}{l}\text { Methionine + } \\
\text { Cystine }\end{array}$ & 3.5 & 0.400 & 1.522 \\
\hline $\begin{array}{l}\text { Phenylalanine } \\
\text { Tyrosine }\end{array}$ & 6.0 & 0.880 & 3.319 \\
\hline Threonine & 4.0 & 0.318 & 1.917 \\
\hline Tryptophan & 1.0 & 0.120 & 1.082 \\
\hline Valine & 5.0 & 0.510 & 2.186 \\
\hline $\begin{array}{l}\text { Biological } \\
\text { value, \% }\end{array}$ & & 94.08 & 77.58 \\
\hline
\end{tabular}

For development of gluten-free confectionery recipes with improved composition, increased bioavailability, optimized by ratio of protein/fat, as well as content of unsaturated (UFA), monounsaturated (MUFA), polyunsaturated (PUFA) fatty acids UFA/MUFA/PUFA apply the principles of food combinatorics.

\section{Food combinatorics}

Simulation of combined products is based on the principles of food combinatorics and aims to create recipes of new types of food products on basis of methods of mathematical optimization by reasonable selection of the basic raw materials, ingredients, food additives and dietary supplements, totality of which ensures formation desired organoleptic, physical and chemical properties product as well as a predetermined level of food, biological and energy value.

Modeling process of combined products recipes includes the following three stages: preparation of input data for the design, formalization requirements for the composition and properties of raw ingredients and quality final product, process modeling; product design with desired structural properties [6].

Application mathematical methods in design of multicomponent products allows you to:

- optimize recipe composition;

- expand range of industrial food products;
- in conditions of deficiency protein-containing raw materials optimize and engage in consumption sphere non-traditional sources raw materials and dietary supplements [7].

\subsection{Mathematical model gluten-free confectionery product with improved composition}

When modeling gluten-free confectionery recipes goal was to optimize chemical composition of finished product, so as align them in ratio of protein to fat, as well as optimize ratio of essential amino acids and fatty acids.

Thus, the goal was in selection prescription weight of recipe components so that product meets following conditions:

- ratio protein weight fraction to fat weight fraction shall be 1,27

$$
\sum_{j=1}^{m} b_{j}^{a} x_{j} / \sum_{j=1}^{m} b_{j}^{f} x_{j}=1.27
$$

where $b_{j}^{a}, b_{j}^{f}$ - weight fraction respectively for protein and for fat in the $\mathrm{j}$-th component; $x_{j}$ - weight fraction of $j$-th component; $m$ - number of components in the recipe.

- ratio weight fraction amino acid lysine to weight fraction amino acids methionine + cystine should trends to one

$$
\sum_{j=1}^{m}\left[a_{l y s}-\left(a_{m e t h}+a_{c y s}\right)\right] \cdot b_{j}^{a} x_{j} \leq e p s
$$

where $a_{l y s}, a_{\text {meth }}, a_{c y s}$ - weight fractions aminoacids lysine, methionine and cystine, gr /100 gr of protein.

- weight fraction aminoacid tryptophan should be less than $1 \mathrm{gr} / 100 \mathrm{gr}$ of protein

$$
\sum_{j=1}^{m} a_{m p n} b_{j}^{a} x_{j} \geq 1
$$

where $a_{m p n}$ - weight fraction aminoacid tryptophan, gr/100 gr of protein.

- ratio weight fractions UFA:MUFA:PUFA = 3:6:1

$$
\begin{aligned}
& 6 \sum_{k=1}^{7} \sum_{j=1}^{m} q_{k j} b_{j}^{f} x_{j}=3 \sum_{k=8}^{10} \sum_{j=1}^{m} q_{k j} b_{j}^{f} x_{j} \\
& \sum_{k=1}^{7} \sum_{j=1}^{m} q_{k j} b_{j}^{f} x_{j}+\sum_{k=8}^{10} \sum_{j=1}^{m} q_{k j} b_{j}^{f} x_{j}=\sum_{k=1}^{13} \sum_{j=1}^{m} q_{k j} b_{j}^{f} x_{j}
\end{aligned}
$$

where $k=1, \ldots, 7$ - corresponds UFA; $k=8,9,10-$ MUFA; $k=11,12,13$ - PUFA; $q_{k j}$ - weight fraction $k$ th fatty acid at $\mathrm{j}$-th component of the formulation, $\mathrm{gr} / 100$ gr of fat. 
As objective function was taken criterion of amino acid correspondence

$$
P(A)=\sum_{k=1}^{n}\left(A_{k}^{0}-\sum_{j=1}^{m} a_{k i} b_{i j} x_{j} / \sum_{j=1}^{m} b_{i j} x_{j}\right)^{2} \rightarrow \min
$$

where $a_{k i}-$ specific content of $\mathrm{k}$-th monostructural ingredient in $i$-th element of chemical composition; $b_{i j}-$ specific content of $i$-th element of chemical composition at $j$-th component designed product.

\subsection{Recipe, food and biological value of modeled food product}

As a result of structural-parametric optimization confectionery product composition by simulation modeling has been obtained gluten-free cookies with the following distribution weight fractions of components in recipe (Table 2) and corresponding chemical composition and biological value (Table 3 ).

Table 2. Recipe of cookie for 100 gr of product

\begin{tabular}{|l|c|}
\hline \multicolumn{1}{|c|}{ Raw materials } & Amount, gr \\
\hline Amaranth flour & 30 \\
\hline Corn starch & 24 \\
\hline Butter & 30 \\
\hline Sugar powder & 8 \\
\hline Walnut & 2 \\
\hline Eggs & 5 \\
\hline Salt & 0,5 \\
\hline Vanillin & 0,5 \\
\hline
\end{tabular}

Table 3. The indicators chemical composition and biological value of cookie

\begin{tabular}{|l|c|}
\hline \multicolumn{1}{|c|}{ Indicator name } & Data \\
\hline Moisture, \% & 16.29 \\
\hline Protein, \% & 4.28 \\
\hline Fat, \% & 24.88 \\
\hline UFA/MUFA/PUFA & $4: 8: 1$ \\
\hline Carbohydrates, \% & 45.18 \\
\hline Energy value, kcal & 340 \\
\hline Essental aminoacids, gr / 100 gr of protein \\
\hline Isoleucine & 2.38 \\
\hline Leucine & 3.65 \\
\hline Lysine & 3.80 \\
\hline $\begin{array}{l}\text { Methionine }+ \\
\text { Cystine }\end{array}$ & 2.66 \\
\hline $\begin{array}{l}\text { Phenylalanine }+ \\
\text { Tyrosine }\end{array}$ & 4.61 \\
\hline Threonine & 2.56 \\
\hline Tryptophan & 1.12 \\
\hline Valine & 2.98 \\
\hline Biological value, \% & 80.99 \\
\hline
\end{tabular}

Selected ratio components of the recipe allowed us to obtain a product with high biological value $(80.99 \%)$ and biological efficiency (ratio UFA/MUFA/PUFA = 4:8:1).

Determination organoleptic (color, taste, smell, shape, surface condition, view of the fracture) and physicochemical (mass fraction of moisture, water absorption) quality indicators developed cookie confirmed its compliance with the requirements of GOST 24901-2014.

\section{Conclusions}

Based on simulation of prescription composition glutenfree biscuits with amaranth flour obtained confectionery recipe having high biological value, as well as optimal ratio protein/fat and UFA/MUFA/PUFA.

Obtained cookies on quality indicators in line with requirements of normative and technical documentation. Thus, developed products will enable to diversify and supplement necessary nutrients diet for people with gluten intolerance, as well as for those who follow a gluten-free diet.

\section{References}

1. G. Serena, S. Camhi, C. Sturgeon, S. Yan, A. Fasano, Nutrients 7(9), 7143-7162 (2015)

2. W. Davis. Wheat Belly: Lose the Wheat, Lose the Weight, and Find Your Path to Health (Rodale Books, 2011)

3. I.A. Nikitin, V.G. Kulakov, E.S. Korovina, A.I. Pisereva. Bread products 11, 29-31 (2016)

4. L.P. Pacshenko, I.A. Nikitin. The success of modern science, 10 (2003)

5. R.U. Uazhanova, U.F. Roslyakov, I.M. Zharkova, N.A. Shmalko. Amaranth - food culture (origin, taxonomy, morphology, physiology, introduction, cultivation, chemical composition, storage, processing, use) (KSTU, 2016)

6. A.I. Zharinov, U.A. Ivashkin. All about meat, 3, 615 (2004)

7. M.E. Titova, M.A. Nikitina, N.A. Tihomirova, Storage and processing of agricultural 7, 41-45 (2013) 